\title{
Delinquency, School Context, and Risk Factors in India, Australia, and the U.S.: Implications for Prevention
}

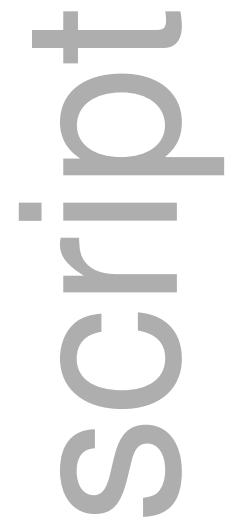

\author{
Michael J. Parks, PhD* \\ Renati J. Solomon, $\mathrm{PhD}^{\mathrm{a}}$ \\ Shreeletha Solomon, $\mathrm{MA}^{\mathrm{b}}$ \\ Bosco C. Rowland, $\mathrm{PhD}^{\mathrm{c}}$ \\ Sheryl A. Hemphill, $\mathrm{PhD}^{\mathrm{d}, \mathrm{e}, \mathrm{f}}$ \\ George C. Patton, $\mathrm{MD}^{\mathrm{e}} \mathrm{f}$ \\ John W. Toumbourou, $\mathrm{PhD}^{\mathrm{g}, \mathrm{h}}$
}

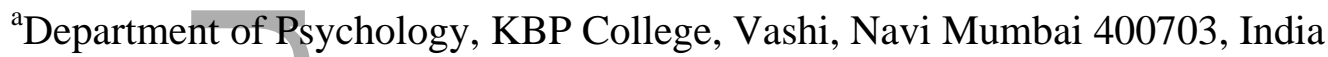

${ }^{\mathrm{b}}$ Institute for Child and Adolescent Health Research, Vashi, Navi Mumbai 400703, India

${ }^{\mathrm{c}}$ Center for Social and Early Emotional Development, School of Psychology, Deakin University, Melbourne Burwood, VIC 3125, Australia

${ }^{\mathrm{d}}$ School of Psychology, Faculty of Health Sciences, Australian Catholic University, 115 Victoria Pde, Fitzroy, Victoria, Australia

${ }^{\mathrm{e}}$ Department of Pediatrics, The University of Melbourne, Parkville, Victoria, Australia

${ }^{\mathrm{f}}$ Centre for Adolescent Health, Murdoch Childrens Research Institute, Parkville, Victoria, Australia

${ }^{\mathrm{g}}$ Deakin University, School of Psychology, Geelong, Victoria, Australia

${ }^{\mathrm{h}}$ Prevention Sciences, Centre for Social and Early Emotional Development, Deakin University, Geelong, Victoria, Australia

*Corresponding author: Division of General Pediatrics \& Adolescent Health, Department of Pediatrics, School of Medicine, University of Minnesota; and Health Promotion and Chronic

This is the author manuscript accepted for publication and has undergone full peer review but has not been through the copyediting, typesetting, pagination and proofreading process, which may lead to differences between this version and the Version of Record. Please cite this article as doi: $\underline{10.1111 / \text { jora. } 12455}$

This article is protected by copyright. All rights reserved 
Disease Division, Minnesota Department of Health, 85 East $7^{\text {th }}$ Place, P.O. Box 64882, Saint Paul, MN 55164, USA. E-mail: Michael.parks@state.mn.us; phone: 651-201-5285.

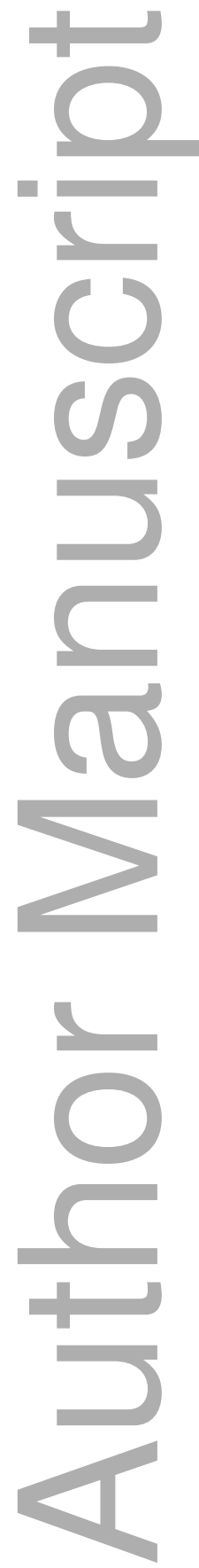




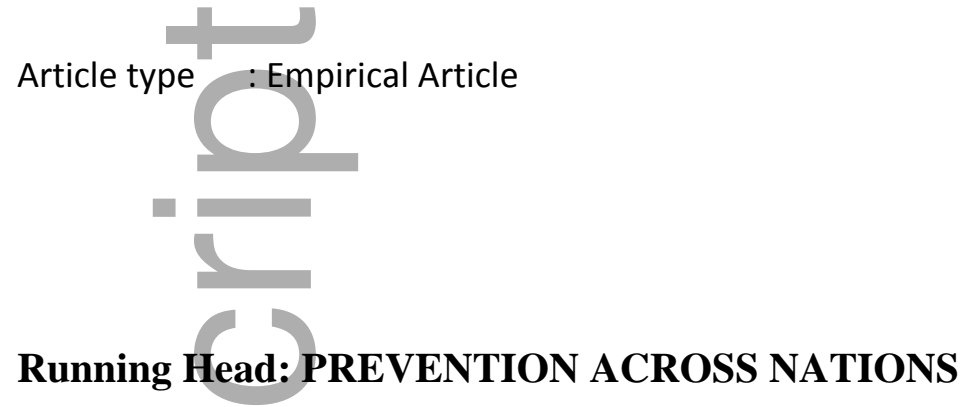

Delinquency, School Context, and Risk Factors in India, Australia, and the U.S.:

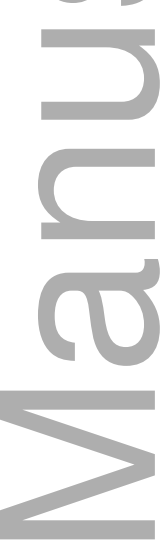

Implications for Prevention

This article is protected by copyright. All rights reserved 


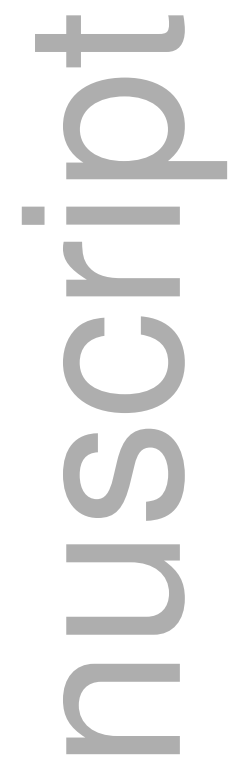

Abstract

There is a dearth of research on delinquency, school context, and risk factors across developed and developing nations. Using representative samples and matched surveys, we examined delinquency among cohorts in Mumbai, India $(\mathrm{N}=3717)$, Victoria, Australia $(\mathrm{N}=1842)$ and Washington State (WA), United States ( $=1828)$. We used multivariate Poisson Hierarchical Linear Modeling. Risk factor and delinquency levels varied across sites. Delinquency clustered within certain schools, particularly in Mumbai. Community disorganization exhibited an association with delinquency as a school-level context effect in Mumbai and Victoria. Peer delinquency, sensations seeking, and poor family management exhibited cross-nationally consistent asssociations with delinquency. Programs that target schools, the clustering of problem behaviors, and cross-nationally consistent risk factors should be considered internationally.

Keywords: adolescent delinquent behavior; prevention science; community disorganization; school context; cross-national prevention; Mumbai; India; adolescent behavioral health 


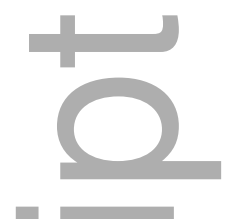

r

\section{Introduction}

Social adjustment in adolescence, including delinquency, predict mortality and health risks into later life (Catalano et al., 2012; Patton et al., 2016; Sawyer et al., 2012). International social trends, such as globalization (e.g., communication, economy), growing inequalities within nations, and urbanization continue to shape profiles of risk for adolescents worldwide by altering environments within which adolescents develop, and by influencing types and levels of risk factors for problem behaviors (Viner et al., 2012; Patton et al., 2016). Put differently, social change occurring across developed and developing nations alike influence the determinants of adolescent health, subsequently affecting the health and social development of adolescents (Viner et al., 2012).

For example, urbanization across the developing world exposes adolescents to risks for problem behavior, most commonly because of changes in community and neighborhood conditions (Parks, 2014; Muggah, 2015; Viner et al., 2012). The developing world has experienced unprecedented rates of urbanization, contributing to inequality through a concentration of poverty in certain neighborhoods (National Research Council, 2003; Parks, 2014). Inequality and poverty have in turn had major health consequences for many urban residents throughout the developing world (Ezeh et al., 2017). These patterns associated with urbanization in addition to other international social change are also important because almost 90\% of adolescents live in developing nations (Patton et al., 2016). Social trends including the internationally large adolescent population and urbanization have led to calls to place a public health priority on the application of prevention science worldwide in order to reduce risks for problem behaviors and subsequent morbidity and mortality (Catalano et al., 2012).

\section{Prevention across Developed and Developing Nations}


An essential step in translating effective interventions from one setting to another is the assessment of risk factors and their relation to targeted problem behaviors in different places (Hawkins, Catalano, \& Arthur, 1992). Yet there is a dearth of cross-national research examining risk factors and their relation to adolescent problem behaviors within both low- and middleincome nations, as the bulk of research on risk factors and their relation to problem behaviors derive from high-income nations (Catalano et al., 2012; Hemphill et al., 2011; Lewis et al., 2017). The objective of this study is to provide a cross-national examination of risk factors in relation to delinquency in order to inform prevention efforts in both developed and developing nations.

Even though adolescent health problems vary across regions, a demonstration of similar social and behavioral risk processes in different sociocultural contexts provides a rationale for the adoption of similar strategies in different places (Leung, Toumbourou, Hemphill, \& Catalano, 2016; Patton et al., 2016; Catalano et al., 2012). We examine these potential similarities in risk factors and their relation to delinquency across nations. Yet equally, crossnational differences in risk factors for delinquency could provide a basis for adaptation of evidence-based programs to different social and cultural contexts. Such differences might arise for a number of reasons, including differences in sociopolitical and cultural contexts, institutions, and educational systems. Consequently, we devote equal attention to potential differences.

We examine risk factors and adolescent delinquent behavior within Mumbai, India as well as two sites in developed nations_-Victoria, Australia, and Washington State (WA), United States (U.S.). Data were examined from Mumbai, India because Mumbai has a disproportionately large youth population that faces multiple burdens of disease, similar to many developing-nation cities (Patton et al., 2016; Lewis et al., 2017). An estimated 230 million people are between the age of 10 and 19 in India, and youth are migrating to cities such as Mumbai (Lewis et al., 2017; National Research Council, 2003). Mumbai is urbanizing rapidly, influencing levels and types of social determinants of adolescent health (Viner et al., 2012; National Research Council, 2003; Ezeh et al., 2017).

We examine Victoria and WA because they offer two locations in developed nations with similar demographic profiles, population sizes, industrial and economic environments, as well as comparable youth populations (see McMorris, Hemphill, Toumbourou, Catalano, \& Patton, 
2007). The two locations also provide different policy contexts that affect levels of behavioral health and risk factors (McMorris et al., 2007; Hemphill et al., 2011); there are also evidencebased prevention programs shown to be effective across the two nations (Catalano et al., 2012).

It is important to note that WA and Victoria are considered to have slightly higher socioeconomic indicators including lower levels of poverty relative to other states within their respective nations (McMorris et al., 2007). In addition, Mumbai is experiencing urbanization at a higher rate compared to other cities in India, which potentially makes Mumbai a unique context to study. However, Mumbai mirrors other cities in India, particularly in regards to adolescent health within urban India (Solomon, Solomon, Minaie, Catalano, \& Toumbourou, 2012).

\section{Conceptual Framework}

We use a conceptual framework that relies on a socioecological approach to health promotion (see Earp \& Ennett, 1991), contending that health related behaviors are shaped by social processes operating at multiple levels (Stokols, 1992). Adolescent health behaviors are embedded within a complex, multilevel system consisting of families, peer groups, schools, and communities (Hawkins et al., 1992; Patton et al., 2016). We draw on the theory of social disorganization, which informs the socioecological approach to health promotion (Stokols, 1992) and stems from socioecological research conducted at the turn of the twentieth century in Chicago (Shaw \& McKay, 1942; Sampson, 2012). That research demonstrated that spatial patterns of crime, violence, delinquency, and infant mortality, are associated with contextual factors such as poverty (Sampson, 2012). More specifically, social disorganization theory espouses three principles relevant for the current project. First, problem behaviors cluster within certain places such as schools and communities (Sampson, 2012; Bradshaw et al., 2009; Stokols, 1992). Second, problem behaviors cluster geographically due to social and physical risk processes such as residential mobility, socioeconomic disadvantage, the place-based clustering of ethnic/racial diversity, as well as community disorganization (Shaw \& McKay, 1942; Sampson, 2012). Third, even though social context is central to the theory, problem behaviors such as delinquency are influenced by multilevel risks in addition to social context (i.e., individual-level factors and contextual factors). These three notions form the foundation for our conceptual framework and analysis. 
Understanding how contexts and multilevel risk factors relate to problem behaviors has become a priority for prevention efforts, and this is the case not only in developed nations such as the U.S. but also in developing regions such as Asia (Leech, 2016; Viner et al., 2012; Ezeh et al., 2016; Parks, 2014; Muggah, 2015). Growing evidence demonstrates the cross-cultural applicability of social disorganization theory in both high and low resource settings (Ezeh et al., 2017; Parks, 2014). The four contextual variables within the framework as previously discussed (residential mobility, socioeconomic status, diversity, and community disorganization) can translate from high-income nations such as the U.S. to low-income nations such as Kenya (Parks, 2014). This cross-cultural applicability is particularly marked within low-income urban areas across both low- and high-income nations (Ezeh et al., 2017; Parks et al., 2014). Yet research must consider how the clustering and the four key variables emphasized within U.S.-based research on social disorganization theory relate to health-risk behavior within local urban communities in low-income nations, as tailoring to the local communities may be required (Parks, 2014; Parks et al., 2014). Subsequently, more research on the conceptual framework's cross-cultural potential is needed (Parks, 2014; Parks et al., 2014).

In the current study, we focus specifically on the contextual influence of schools. School contexts garner attention as they reflect community characteristics and they can have a profound impact on adolescent development and health (Viner et al., 2012; Leventhal \& Brooks-Gunn, 2000; Ennett, Flewelling, Lindrooth, \& Norton, 1997). In addition, adolescent problem behaviors cluster within certain schools (Ennett et al., 1997; Bradshaw, Sawyer, \& Brennan, 2009). We also focus on schools for programmatic reasons. The extensive school-based prevention programs evaluated in both Victoria and WA could potentially translate to low income nations, if school contexts can be shown to relate to problem behaviors in cross-nationally similar ways.

Even though our conceptual framework originated from community-level research, a framework rooted in social disorganization theory is relevant for studying school context and adolescent behavioral health (Bradshaw et al., 2009). Schools can operate as proxies for neighborhoods and communities, as school and community characteristics are interrelated. For instance, school environments are influenced by the characteristics of surrounding neighborhoods, and this is particularly the case in regards to schools' influence on adolescent problem behaviors (Bradshaw et al., 2009; Ennett et al., 1997; Sampson, 2012). More 
importantly, social disorganization theory is applicable to schools because adolescent problem behaviors cluster within schools, and schools marked by social disorganization are conducive to delinquency and other problem behaviors (Ennett et al., 1997; Bradshaw et al., 2009).

Since the socioecological framework and social disorganization theory emphasize multilevel influences, we evaluate school contexts and individual-level risk factors simultaneously. We rely on additional prevention models to identify risk factors that include psychological mechanisms, peer-group factors, and family characteristics associated with delinquent behavior (Catalano \& Hawkins, 1996; Jessor, 1991). To our knowledge, there is only one research project that examined how a prevention model (i.e., problem behavior theory) from the U.S. could be used to study adolescent problem behavior in a developing-nation city, and results indicated that U.S.-based prevention models can translate to low-income nations (see Ndugwa et al., 2010). However, this previous research primarily focused on the role of risk factors at the individual level, and it was limited to a single data set in sub-Saharan Africa.

\section{The Current Study}

The current paper has three primary aims. First, we compare mean levels of delinquent behavior and risk factors across Mumbai, India, Victoria, Australia, and WA, United States. Second, we assess the clustering of delinquent behavior within schools, and we compare these analyses across the three locations. Third, we examine how school context factors identified by social disorganization theory relate to delinquent behavior, as well as assess how other risk factors measured at the individual level relate to delinquent behavior in the three locations.

Previous research has demonstrated that Victoria and WA exhibit relatively comparable levels of delinquent behavior (McMorris et al., 2007). Considering existing cross-national data on adolescent health (e.g., in sexual health and substance use), we would suspect that rates of problem behaviors would be lower in India compared to Australia and the U.S. (Patton et al., 2012). However, there is a dearth of research on adolescent problem behaviors across low- and high-income nations, particularly at a granular level that compares smaller locales such as Mumbai to matched states or cities (Patton et al., 2016; Patton et al., 2012). Based on previous research (Hemphill et al., 2011), we suspect that levels of risk factors should be relatively comparable between WA and Victoria. Because of social trends such as rapid urbanization within low- and middle-income nations, certain urban areas have exhibited high levels of risk 
factors identified by social disorganization theory, such as neighborhood socioeconomic status and community disorganization (National Research Council, 2003). Therefore, we hypothesized that Mumbai would exhibit higher levels of risk factors identified within social disorganization theory.

Considering research on the clustering of health and social issues within certain areas of developed nations (Sampson, 2012) as well as developing-nation cities (National Research Council, 2003; Parks, 2014), we hypothesize that delinquent behavior will cluster within certain schools across all locations. The degree of clustering across sites is less predictable. For instance, research from urban neighborhoods in sub-Saharan Africa demonstrates that clustering could be more pronounced within a developing-nation city (see Parks, 2014), but there are dramatic disparities across locales within developed-nation cities as well (Sampson, 2012). Consequently, we limited our hypothesis to predicting the common presence of clustering, and do not make a hypotheses regarding the degree of clustering. Finally, we hypothesize that our conceptual framework will apply across nations. Previous research has indicated that risk factors identified within our conceptual framework can translate across WA and Victoria; moreover, research demonstrates that social disorganization theory can be applied within both developed and developing nations (see Parks, 2014; Ndugwa et al., 2010; Hemphill et al., 2011). Therefore, we hypothesize that school contexts and other risk factors that we examine will similarly relate to delinquency across locations, in that the direction and magnitude of relationships will be crossculturally consistent. Local contexts and cross-cultural differences can create unique circumstances that do not perfectly match U.S.-based theories, but the variables identified by social disorganization theory have cross-national applicability (Parks et al., 2014; Parks, 2014).

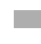

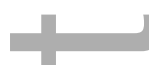

\section{Methods}

\section{Data and Participants}

Data came from the International Youth Development Study (IYDS), which offers a standardized research design for cross-national comparisons (McMorris et al., 2007). IYDS is a tri-national study geared toward documenting and comparing youth development and health behavior, utilizing equivalent cohorts in Mumbai, Victoria, and WA. The IYDS is rooted in principles from the field of prevention science (see Catalano \& Hawkins, 1996), with a focus on multilevel risk and protective factors and adolescent behavioral health (McMorris et al., 2007). 
The study augmented the Communities That Care (CTC) Youth Survey (Hawkins, Catalano, \& Arthur, 2002) with harmonized sampling, administration, and follow-up methods. Victoria and WA were included in an original cohort (McMorris et al., 2007; Hemphill et al., 2011), and Mumbai was added later (Solomon et al., 2012). While the focus of CTC is on multilevel risk and protective factors that span from the individual to the community level, the sampling process for CTC captured identifiers for schools and individuals - i.e., two levels of data.

The survey was originally implemented in 2002 within Victoria and WA. To ensure representativeness in Victoria and WA, fifth-, seventh-, and ninth-grade students from private and public schools were randomly selected using a probability sampling procedure that was proportionate to grade-level size (McMorris et al., 2007). A two-stage stratified sampling procedure was used: at the first stage, schools were randomly selected, and at the second stage, classrooms were randomly selected within schools. Replacement schools were recruited if recruitment of sampled schools was unsuccessful. More details on sampling procedures and data collection are available elsewhere (McMorris et al., 2007; Lewis et al., 2017; Solomon et al., 2012). Permission to conduct the study within classes for Grades 7 and 9 was initially received from Washington State school districts and relevant education authorities for Victorian schools (McMorris et al., 2007).

Following past research (Lewis et al., 2017), we limited the sample to seventh- and ninthgrade students in order to examine adolescence (ages 12 to 16), and because delinquency assessments differed for fifth-grade students. We pooled seventh and ninth grades and examined a single sample of adolescents for each location. Of approached students, $78 \%$ and $76 \%$ from WA and Victoria, respectively, were recruited following informed parental consent from the seventh- and ninth-grade cohorts ( $\mathrm{N}=1942$ WA, $\mathrm{N}=1957$ Victoria). We used listwise deletion for missing data and eliminated students with dishonest answers. Students were marked as dishonest if they did any of the following: 1) answered a self-report question that asked whether they were not honest when filling out the survey; 2) used a fake drug added to the survey; or 3) used illicit drugs on more than 120 occasions in the past 30 days (McMorris et al., 2007; Lewis et al., 2017). Less than $5 \%$ of the sample from each site was excluded due to missing data and honesty concerns. The final analytic samples for Victoria and WA were, respectively: individual $\mathrm{N}=1842$, school $\mathrm{N}=102$; and individual $\mathrm{N}=1828$, school $\mathrm{N}=97$. 
In response to the growing need for comparable data across developing and developed nations in regards to global adolescent health, the research team for IYDS developed a partnership with researchers in Mumbai to begin exploring how research findings from WA and Victoria compare to India. The research team had already established a partnership between WA and Victoria, which produced datasets with matched survey items, sampling methodology, and sample sizes. A subsequent partnership was established within Mumbai. The Mumbai arm of the IYDS was implemented in 2010-2011. An equivalent procedure was used to recruit the Mumbai sample (89\% recruited; $\mathrm{N}=3918$ ) with school standards 7 and 9 within Navi Mumbai and greater Mumbai in Maharahstra (which were equivalent to U.S. school grades or Australian school grades/years). The augmented CTC Youth Survey and matching methodological procedures were also used for the Mumbai study, which provided common surveys, method administration, and youth samples in order to make cross-national comparisons with cohorts from the original IYDS study in Victoria and WA. Moreover, we employed methods to address methodological errors commonly found in cross-cultural research such as cognitive pre-testing in all countries to ensure semantic equivalence of items.

There are time differences in terms of the data-gathering periods, but the Mumbai study was successful in its attempt to generate a sample designed for cross-national comparisons (Lewis et al., 2017; Solomon et al., 2012). Approval was received from the Mumbai government and selected schools; consent was received from parents of potential participants. Less than $5 \%$ of the sample from Mumbai was excluded due to missing data and honesty concerns. The final analytic sample for Mumbai was: individual $\mathrm{N}=3717$, school $\mathrm{N}=98$.

\section{Measures}

Outcome measure: Adolescent delinquent behavior. Delinquent behavior was measured via the "variety scoring" method, which was a count of the number of delinquent acts committed in the past 12 months (Sweeten, 2012). The count is based on the cumulative number of delinquent acts, assessed by the following 10 binary measures $(1=$ yes, $0=$ no $)$ : carried a handgun, carried a weapon, stole something worth \$AUS5/\$US10+, sold illegal drugs, stole a vehicle, attacked someone, got drunk or high at school, brought handgun to school, beat someone so badly they needed to go to a doctor, threatened someone with a weapon. 
School-context and social disorganization measures. Based on previous research (Bradshaw et al., 2009; Ennett et al., 1997; O’Malley, Johnston, Bachman, Schulenberg, \& Kumar, 2006), we aggregated the following individual-level measures to the school level: community disorganization, residential mobility, and parents' education. Community disorganization was a scale of four questions regarding students' neighborhoods, which assessed empty or abandoned buildings, graffiti, fights, and crime and/or drug selling (Mumbai $\alpha=.69 ; \alpha$ $=.82$ for WA and Victoria). Residential mobility was a scale of two questions about changing schools and homes in the past year (Mumbai $\alpha=.65 ; \alpha=.62$ for WA and Victoria). More details about these scales and their properties are available in previous publications (McMorris et al., 2007; Solomon et al., 2012; Arthur, Hawkins, Pollard, Catalano, \& Baglioni, 2002; Glaser, Van Horn, Arthur, Hawkins, \& Catalano, 2005). Parents' education was standardized across countries using a three-category breakdown of highest level of education achieved, averaged across parents. We aggregated this to measure school-level socioeconomic status (see O'Malley et al., 2006).

We created separate measures of school diversity for each study site. School diversity was based on race/ethnicity for Victoria and WA; religion and caste were used for India. Diversity was assessed via the entropy measure (see Reardon \& Firebaugh, 2002). The measure captures the degree to which schools are composed of multiple groups (i.e., the likelihood that two randomly selected individuals would come from the same group). High scores indicate high levels of diversity (racial/ethnic, religious, caste) and low scores indicate homogeneity. The distribution and descriptive statistics for each measure are displayed in Table 1.

Other risk factors. Other risk factors were identified following models of prevention science (Catalano \& Hawkins, 1996; Jessor, 1991), and included, low student school commitment, student sensation seeking, peer delinquency, peer substance use, and poor family management measured at the individual level. Each measure was a continuous scale. Low student school commitment measured how meaningful school work was, interest in school subjects, perceptions of school importance later in life, enjoyment of school, and effort in school (Mumbai $\alpha=.48 ; \alpha=.76$ for WA and Victoria). Student sensation seeking consisted of three questions about frequency of health-risk behaviors: "did crazy things even if dangerous," "did something dangerous on dare," and "did what feels good no matter what" (Mumbai $\alpha=.62 ; \alpha=$ 
.75 for WA and Victoria). Peer delinquency consisted of six questions about friends' delinquent behavior in the past year (Mumbai $\alpha=.62 ; \alpha=.72$ for WA and Victoria). Peer substance use consisted of four questions about friends' substance use in the past year (cigarettes, alcohol, marijuana, and other illegal drugs) (Mumbai $\alpha=.68 ; \alpha=.79$ for WA and Victoria). Poor family management consisted of nine questions regarding clarity of behavioral rules, monitoring, and rewards for positive behavior, among others (Mumbai $\alpha=.78 ; \alpha=.81$ for WA and Victoria).

Previous research has confirmed the psychometric utility of the CTC survey and the scale attributes (Arthur et al., 2002; Glaser et al., 2005), as well as the consistency of measurement characteristics across the sites (Hemphill et al., 2011; McMorris et al., 2007; Solomon et al., 2012).

Individual-level demographics. Individual-level demographics included age, gender, race/ethnicity, religion, urban versus non-urban, and parents' education. All means and standard deviations are presented in Table 1. Age is a continuous measure; all other measures were treated as categorical variables. Race/ethnicity was included only in Australia (Australian $=1$, other $=0$ ) and the U.S. (white $=1$, non-white $=0$ ), and religion was included only in India (Hindu $=1$, other $=0$ ). Urban versus non-urban was used only in Victoria and WA as the Mumbai sample was completely urban. Parents' education was standardized across countries using a threecategory breakdown of highest level of education achieved, averaged across parents: (1) primary, (2) secondary, or (3) tertiary. Primary school was the reference group in regression analyses.

\section{Analytic Strategy}

In accordance with our first research aim of assessing delinquency and risk factors across countries, we examined delinquent behavior via descriptive analyses as well as ANOVAs, consisting of all three locations combined into a single dataset. We used the Bonferroni correction in order to account for the multiple comparisons, which ensured accurate tests of statistical significance. Since the delinquency outcome was a count measure, we analyzed prevalence estimates across sites using predicted values derived from Poisson regression models, adjusting for age and sex.

Regarding our second aim to assess school-level context and the clustering of adolescent delinquent behavior, we examined delinquent behavior via Hierarchical Linear Modeling 
(HLM). The IYDS had a nested structure with students nested within schools. We distinguish schools and students as nested levels of analysis with two-level random-intercept HLM models, including random effects that allow for residual variance at both levels (Raudenbush \& Bryk, 2002). For the count measure, we employ Poisson HLM models (with overdispersion), which produces event rate ratios (ERR). ERRs are exponentiated Poisson regression coefficients (log of ratio of expected counts). We ran null HLM models to assess the clustering of delinquent behavior within schools (Table 2).

In order to examine how both individual-level factors as well as the school context factors identified by the social disorganization framework relate to delinquent behavior, we ran full HLM models that included individual-level and school-level variables. To assess social disorganization risk factors of socioeconomic status and diversity, we included socioeconomic status and diversity measures at the school level and considered how total between-school differences related to delinquency. To examine social disorganization factors of community disorganization and mobility, the two measures were included in both individual- and schoollevel equations (centered on their grand mean), resulting in "context effects" since school-level intercepts were adjusted for between-school differences. The full HLM models also allowed us to include demographics and other risk factors within the individual-level equation. Since these measures were included in the individual-level equation, the full HLM models also adjusted for school composition in terms of gender, age, and urban residence because each variable was centered on their overall mean (all other variables were centered on their school means).

Finally, we ran secondary models that allowed the relationships among individual-level risk factors and delinquency to vary randomly across schools, which analytically was represented through random slopes. These random intercept and random slope models also served as a robustness check for the primary analyses (i.e., we tested whether the primary results changed after accounting for variance in slopes).

\section{Results}

\section{Descriptive Results}

Table 1 presents descriptive statistics. Adolescents in Mumbai reported the lowest unadjusted level of delinquent behavior compared to both Victoria and WA (M $=0.25$ vs. 0.48 
and 0.54 , respectively). These differences remained relatively unchanged after adjusting for age and gender. The predicted values of the Poisson regression models showed that adjusted estimates for Mumbai, Victoria, and WA, respectively, were 0.24 (95\% CI = 0.22, 0.26), 0.48 $(95 \% \mathrm{CI}=0.44,0.51)$, and $0.53(95 \% \mathrm{CI}=0.49,0.56)$. Mumbai exhibited a significantly lower level of delinquent behavior compared to both Victoria and WA ( $p<0.001$ ); Victoria and WA did not differ in their levels of delinquent behavior $(\mathrm{p}>0.3)$. In terms of differences across countries in the types of acts included in the delinquency measure, only a few differences emerged: Victoria and WA had slightly higher percentages of adolescents who committed theft, carried a weapon, and got drunk or high at school relative to India. For Mumbai youth, the three most common acts were: beaten someone badly (5.0\%), carried a weapon (4.1\%), and attacked someone (4.0\%). For Victoria and WA youth, the two most common acts were committed theft (Victoria $=12.7 \%, \mathrm{WA}=13.3 \%$ ) and carried a weapon (Victoria $=10.9 \%, \mathrm{WA}=12.4 \%$ ); the third most common acts in Victoria and WA were attacked someone $(6.1 \%)$ and got drunk or high at school $(6.7 \%)$, respectively.

\section{[TABLE 1 ABOUT HERE]}

As shown in Figure 1, the unadjusted means reported in Table 1 for social disorganization measures of socioeconomic level (parents' education) and mobility significantly differed across all three cities (ps $<0.001$ ), and community disorganization differed only for Mumbai versus both Victoria and WA ( $<<0.001)$. Mumbai had the highest level of community disorganization and the lowest levels of parents' education and mobility compared to Victoria and WA; WA had the highest levels of education and mobility.

\section{[FIGURE 1 ABOUT HERE]}

Figure 2 demonstrates that other risk factors of low student school commitment, student sensation seeking, and peer delinquency differed significantly only for Mumbai compared to WA and Victoria; the differences were not significant between Victoria and WA. Mumbai exhibited the lowest levels of each risk factor (ps $<0.001$ ). Peer substance abuse and poor family management differed across all three locations (ps $<0.001)$. Victoria adolescents reported the highest level of peer substance abuse, and Mumbai adolescents reported the highest level of poor family management. Means are displayed in Table 1. 
[FIGURE 2 ABOUT HERE]

\section{Multilevel Results}

Table 2 reports null HLM models. There was significant and substantial variance in delinquency across schools in all three sites. The majority of variance existed at the individual level, with each location displaying comparable results for individual-level variance. Mumbai had the highest amount of school-level variance and the largest intraclass correlation coefficient compared to Victoria and WA (0.273 vs. 0.157 vs. 0.059 , respectively).

\section{[TABLE 2 ABOUT HERE]}

Table 3 displays full HLM models. At the school level, the context effect of community disorganization was significantly related to delinquent behavior within Mumbai and Victoria $(\mathrm{ERR}=7.92,95 \% \mathrm{CI}=3.55,17.66$; and $\mathrm{ERR}=3.42,95 \% \mathrm{CI}=1.41,8.29$, respectively $)$, but it was non-significant for WA. Put differently, above and beyond individual-level measures, school-level community disorganization predicted delinquency in Mumbai and Victoria, adjusting for individual- and school-level covariates. Socioeconomic level at the school level was significantly related to delinquency in Victoria $(\mathrm{ERR}=0.71,95 \% \mathrm{CI}=0.51,0.99)$, and the context effect of mobility at the school level was significant in WA $(\mathrm{ERR}=1.56,95 \% \mathrm{CI}=1.18$, 2.08).

Individual-level associations were comparable in all cities. Risk factors related to family and school bonds were significant predictors of delinquency. Student sensation seeking, peer delinquency, and poor family management were positively related to delinquent behavior in each site, with comparable event rate ratios (all ERRs reported in Table 3). Peer substance abuse was positively and significantly related to delinquency in Victoria and WA; it was non-significant in Mumbai. Parent education at the individual level was a significant predictor only in Victoria. Community disorganization at the individual level exhibited significant associations in all cities, with the event rate ratio highest in Mumbai compared to Victoria and WA.

\section{[TABLE 3 ABOUT HERE]}

Secondary analyses that allowed the relationships among individual-level risk factors and delinquency to vary across schools showed that the primary results were robust. In Mumbai, the 
slopes for all of the individual-level risk factors varied significantly across schools. In Victoria, all individual-level risk factors varied significantly across schools, except the slope for student sensation seeking. In WA, the slopes for community disorganization, peer delinquency, peer substance abuse, and student sensation seeking significantly varied across schools.

\section{Discussion}

This project comparatively examined adolescent delinquent behavior in Mumbai, India, Victoria, Australia, and WA, U.S., focusing on school context and risk factors measured at the school and individual level. We found mean delinquency was lower in Mumbai relative to Victoria and WA, supporting our hypothesis. This finding supports research demonstrating that India has lower levels of problem behaviors compared to developed nations (Patton et al., 2012), and we add to this literature by providing cross-national comparisons using data sets with matched survey items and sampling methodologies. We also found levels of risk factors varied across the three locations. Community disorganization was highest in Mumbai, but Mumbai also exhibited the lowest levels of all other risk factors with the exception of poor family management. Victoria and WA had similar levels of risk factors, supporting previous research (Hemphill et al., 2011).

Delinquent behavior clustered markedly within certain schools across all locations (second research aim), supporting previous research and the cross-cultural applicability of our conceptual framework (Ezeh et al., 2016; Parks, 2014; Parks et al., 2014). Clustering was most pronounced in Mumbai, but delinquency clustered within certain schools to a nontrivial degree in all three sites. Approximately $27 \%$ of the variance in delinquency was at the school level within Mumbai, compared to approximately $16 \%$ and $6 \%$ in Victoria and WA, respectively. There are no clear guidelines for gauging the size of an intraclass correlation coefficient (e.g., Nezlek, 2008), but a minimum of $3 \%$ of variance at a higher unit of analysis is typically considered sizeable (e.g., see Niehaus, Campbell, \& Inkelas, 2014). The import for the current discussion is that delinquency clustered within schools across all three sites; moreover, the relationships between risk factors and delinquency varied across schools in all locations.

Clustering was more marked within Mumbai and Victoria relative to WA. This difference could be the result of the unique context within Mumbai. Previous research demonstrates that rapid urbanization in developing nations can spawn pronounced clustering of health and social 
problems within certain urban areas, as well as elevated levels of risk factors such as community disorganization (Muggah, 2015; Ezeh et al., 2016; Parks, 2014; National Research Council, 2003). Even though delinquency was on average lower within Mumbai, risk factors such as community disorganization were higher in Mumbai and the clustering of delinquency was more substantial. The major implication from these results is that schools are important sites for prevention in all three locations, but the influence of school context varies most substantially in Mumbai. Despite initially low levels of delinquency, tailored prevention efforts that carefully assess school context and elevated risk factors could prevent delinquency from increasing as Mumbai continues to urbanize. While schools are important, we highlight here that schools can also serve as a proxy for community and neighborhood context, particularly in regards to their association with adolescent health behavior (Ennett et al., 1997). Therefore, even though we only assessed the context of schools, previous research suggests that our findings could extend to communities because of the overlap between school and community contexts.

In line with our third aim, risk factors identified by the social disorganization framework were related to delinquent behavior across all three sites. The measure of community disorganization was consistently associated with delinquency in the form of a school-level context effect, supporting a central tenant of our framework that the school-level measure of disorganization is an important contextual risk factor across nations and sociocultural contexts. In terms of other risk factors identified by the social disorganization perspective, school-level socioeconomic status was important in Victoria, and residential mobility context effects were unique to WA.

It is important to consider the potential influences of national policy and sociocultural environments in relation to our findings. Residential mobility at the school level was related to delinquency only in WA, and residential mobility is known as a risk factor for problem behaviors in the U.S. (Sampson, 2012). Residential mobility is not a consistent risk factor for problem behaviors within developing-nation cities (Parks, 2014), and we found residential mobility at the school level was not related to delinquency in Mumbai. In addition, socioeconomic differences across schools were only important in Victoria, which could be the result of unique dynamics of inequality within Australia. We also found that Victoria and WA had higher levels of certain risk factors relative to Mumbai, which could be the result of national policy as well as culture, among 
others such as educational systems and national institutions (Hemphill et al., 2011; McMorris et al., 2007). For instance, Australia and the U.S. along with other developed nations tend to have higher levels of adolescent substance abuse (e.g., alcohol) relative to India (Patton et al., 2012), and our findings on elevated risk factors such as peer substance abuse within Victoria and WA support this notion.

Keeping with our third aim, we also found support for our hypothesis that other risk factors associated with individual, peer, and family characteristics would be related to adolescent problem behaviors in all locations, with comparable effect sizes. Associating with delinquent peers was consistently related to delinquency, supporting previous research (Sawyer et al., 2012; Jessor, 1991; Catalano \& Hawkins, 1996). Student sensation seeking and family management emerged as important and consistent factors across all locations. This project provides evidence that modifiable risk factors identified in U.S.-based prevention models such as the social development model and problem behavior theory (Jessor, 1991; Catalano \& Hawkins, 1996), are relevant for adolescent behavioral health in Mumbai, adding to previous cross-national research in North America, Australasia, and Africa (Ndugwa et al, 2010; Hemphill et al., 2011).

\section{Implications for Prevention and Health Promotion}

There are specific implications regarding our findings on contextual risk factors and the clustering of delinquency within certain schools within Mumbai. Delinquency was lowest in Mumbai, but delinquency clustered most dramatically within Mumbai. Mumbai also had the highest level of community disorganization, which related to delinquency as a context effect and an individual-level risk factor. This suggests that a targeted prevention approach would be optimal in Mumbai, whereas more universal strategies would be more appropriate in WA and Victoria. For instance, targeted programs that carefully assess different schools could address the impact of community disorganization and pronounced clustering of problem behaviors in Mumbai. That is, even if delinquency is generally lower in Mumbai, there are certain areas that have elevated levels of delinquency and risk factors associated with delinquency. The "busy streets" initiative used in the U.S. is a targeted prevention program that can reduce risk factors such as community disorganization and its structural antecedents (see Aiyer, Zimmerman, Morrel-Samuels, \& Reischl, 2015). Addressing these risk factors through the busy streets program has potential to reduce problem behaviors such as violence (see Culyba et al., 2016). 
Programs such as "busy streets" may need to be adapted in order to tailor the program and its components to the local context in an attempt to translate the program from the U.S. to a developing-nation city, as constructs and social dynamics may not uniformly apply to urban communities across developed and developing nations (Parks, 2014; Parks et al., 2014).

Another implication concerns the need to address multilevel risk factors. Prevention programs such as Communities That Care (CTC) can address multilevel risk factors (Hawkins et al., 2002; Oesterle, Hawkins, Fagan, Abbott, \& Catalano, 2014). Our findings highlight that risk factors at multiple levels consistently relate to delinquency across all three sites - risk factors ranging from individual to family characteristics were similarly associated with delinquency in Mumbai, Victoria, and WA. The implication is that a framework such as CTC could serve as an effective prevention initiative for addressing multiple risk factors in Mumbai, as the CTC program was successfully implemented in both the U.S. and Australia (Catalano et al., 2012). The CTC framework could also potentially serve as a useful tool within cities such as Mumbai because the program aims to encourage local communities to implement evidence-based programs chosen by local communities in accordance with their community capacity, and based on local data. This process of local participation could account for potential cultural differences.

\section{Limitations}

There are cross-cultural and regional differences that can influence cross-national survey methods, and there is a rich literature that delineates the pitfalls and solutions to such methodological issues (see Harkness, Van de Vijver, \& Mohler, 2003). Differences in social cognition, communication styles, and social desirability across cultures are just a few examples of methodological issues that cross-national researchers face (Harkness et al., 2003). Our goal was to address the need for more cross-nationally comparable data within adolescent health in order to make granular-level comparisons (Patton et al., 2012), and we employed methods in order to avoid methodological errors commonly found in cross-cultural survey research.

For instance, the IYDS was initiated in all nations with cognitive pre-testing to ensure semantic equivalence of items. The scales and measures used in the current analysis showed similar inter-item associations, and we found similar cross-nation associations between most scales and delinquency. It is important to note that some scales were less reliable in Mumbai (i.e., lower alphas) compared to Victoria and WA (e.g., low school commitment scale). Put 
differently, the meaning of different measures could vary across nations and cultures, but the IYDS methodology produced cohorts with comparable survey data, and it is unlikely that the national differences arise due to self-reporter differences. We also used survey adaptation and translation in order to tailor survey questions to the local contexts of WA, Victoria, and Mumbai that still ensured cross-national comparability (see Harkness et al., 2003). However, it is still possible that not all constructs translate perfectly across countries.

The data reported here were cross-sectional samples and self-reported data from youth. Our results should be interpreted in this vein - the relationships were associations and not causal relationships, and we did not rely on alternative forms of data collection (e.g., observational data, teacher-reported data). In addition, as previously noted, there was a gap between the time when data were initially gathered in Victoria and WA compared to Mumbai. While our interest was primarily in how risk factors relate to delinquency, which was unlikely to have changed over this time period, it is possible that levels of risk factors and delinquency may have shifted.

Future research should continue to explore how conceptual frameworks rooted in social disorganization apply across countries and cultures as it has potential to help document the consequences of social trends such as rapid urbanization occurring across the developing world (Ezeh et al., 2016). Specific to adolescent problem behavior, future research should continue to explore the clustering of health and social problems in rapidly growing cities within developing nations, such as Mumbai. Research should also continue to utilize harmonized surveys that allow for more cross-national comparisons of adolescent health problems at a granular level to compare different cities and states (Patton et al., 2012). Finally, future research should begin testing the utility of evidence-based prevention programs that can address school contexts as well as multilevel risk factors across developed and developing nations (Catalano et al., 2012; Viner et al., 2012).

\section{Conclusion}

Adolescent problem behaviors vary across countries and regions, but they similarly affect morbidity and mortality worldwide (Catalano et al., 2012). Less is known about delinquency and risk factors across developed and developing nations, in part because of limited data at a granular level that allows for cross-national comparisons (Patton et al., 2012). Using cross-nationally comparable surveys, we found delinquency was lowest in Mumbai relative to Victoria and WA. 
Risk factors also varied across the sites. Mumbai had the highest level of community disorganization, while Victoria and WA had higher levels of other risk factors such as peer substance abuse and student sensation seeking.

We found that delinquency clustered within certain schools across all sites, with Mumbai demonstrating the highest degree of clustering. While the clustering of delinquency within certain schools was less marked within Victoria and WA, there was nontrivial clustering within each of these sites.

School context socioeconomic status related to delinquency in Victoria and school context residential mobility relates to delinquency in WA. School contexts marked by community disorganization was a critical risk factor for delinquency within Mumbai. Even though Mumbai had lower levels of delinquency, the greater degree of clustering and higher levels of community disorganization implied that targeted prevention would be optimal in Mumbai. As Mumbai continues to urbanize, it is possible risk factors will increase and the clustering of problem behaviors could become more pronounced. Consequently, targeted programs that carefully assess school context and risk factors such as community disorganization could reduce delinquency in areas with elevated levels of delinquency and risk factors within urbanizing Mumbai.

We found that our conceptual framework translates across nations and sociocultural contexts. Not only did we find that delinquency clusters within schools across all three sites, but we also found common multilevel risk factors that relate to delinquency across sites with similar effect sizes. Risk factors that include individual characteristics, peer influences, and family dynamics similarly relate to delinquent behavior in Mumbai, Victoria, and WA. Future research should continue to examine cross-cultural differences in adolescent behavioral health and risk factors, as well as test the cross-national applicability of evidence-based prevention programs across the three locations. Research should also focus on tailoring both universal and targeted prevention programs across developed and developing nations. 


\section{References}

Aiyer, S. M., Zimmerman, M. A., Morrel-Samuels, S., \& Reischl, T. M. (2015). From broken windows to busy streets: A community empowerment perspective. Health Education \& Behavior, 42, 137-147.

Arthur, M. W., Hawkins, J. D., Pollard, J. Catalano, R. F., \& Baglioni, A. J. (2002). Measuring risk and protective factors for substance use, delinquency, and other adolescent problem behaviors: The Communities That Care Youth Survey. Evaluation Review, 26, 575-601.

Bradshaw, C. P., Sawyer, A. L., \& O’Brennan, L. M. (2009). A social disorganization perspective on bullying-related attitudes and behaviors: The influence of school context. American Journal of Community Psychology, 43, 204-220.

Catalano, R. F., Fagan, A. A., Gavin, L. E., Greenberg, M. T., Irwin, C. E., ..., Shek, D. T. L. (2012). Worldwide application of prevention science in adolescent health. Lancet, 379, 1653-1664.

Catalano, R. F., \& Hawkins, J. D. (1996). The social development model: A theory of antisocial behavior. In J. D. Hawkins (Ed.), Delinquency and crime: Current theories (pp. 149197). New York, NY: Cambridge University Press.

Culyba, A. J., Jacoby, S. F., Richmond, T. S., Fein, J. A., Hohl, B. C., \& Branas, C. C. (2016). Modifiable neighborhood features associated with adolescent homicide. JAMA Pediatrics, 170, 473-480.

Earp, J. A., \& Ennett, S. T. (1991). Conceptual models for health education research and practice. Health Education Research, 6, 163-171.

Ennett, S. T., Flewelling, R. L, Lindrooth, R. C., \& Norton, E. C. (1997). School and neighborhood characteristics associated with school rates of alcohol, cigarette, and marijuana use. Journal of Health and Social Behavior, 38, 55-71.

Ezeh, A., Oyebode, O., Satterthwaite, D., Chen, Y.-F., Ndugwa, R., ..., Lilford, R. J. (2017). The history, geography, and sociology of slums and the health of people who live in slums. Lancet, 389, 547-558.

Glaser, R. R., Van Horn, M. L., Arthur, M. W., Hawkins, J. D., \& Catalano, R. F. (2005). Measurement properties of the Communities That Care Youth Survey across demographic groups. Journal of Quantitative Criminology, 21, 73-102.

Harkness, J. A., Van de Vijver, F. J. R., \& Mohler, P. P. (2003). Cross-cultural survey methods. 
Hoboken, N. J.: John Wiley \& Sons, Inc.

Hawkins, J. D., Catalano, R. F., \& Arthur, M. W. (2002). Promoting science-based prevention in communities. Addictive Behaviors, 27, 951-976.

Hemphill, S. A., Heerde, J. A., Herrenkohl, T. I., Patton, G. C., Toumbourou, J. W., \& Catalano, R. F. (2011). Risk and protective factors for adolescent substance use in Washington State, United States and Victoria, Australia: A longitudinal study. Journal of Adolescent Health, 49, 312-320.

Jessor, R. (1991). Risk behavior in adolescence: A psychosocial framework for understanding and action. Journal of Adolescent Health, 12, 597-605.

Leech, T. G. J. (2016). Beyond collective supervision: Informal social control, prosocial involvement, and juvenile offending in urban neighborhoods. Journal of Research on Adolescence, 26(3), 418-431.

Leung, R. K., Toumbourou, J. W., Hemphill, S. A., Catalano, R. F. (2016). Peer group patterns of alcohol-using behaviors among early adolescents in Victoria, Australia, Washington State, United States. Journal of Research on Adolescence, 26(4), 902-917.

Leventhal, T., \& Brooks-Gunn, J. (2000). The neighborhoods they live in: The effects of neighborhood of residence on child and adolescent outcomes. Psychological Bulletin, 126, 309-337.

Lewis, A. J., Rowland, B., Tran, A., Solomon, R. F., Patton, G. C.,.., Toumbourou. (2017). Adolescent depressive symptoms in India, Australia, and USA: Exploratory structural equation modelling of cross-national invariance and predictions by gender and age. Journal of Affective Disorder, 212, 150-159.

McMorris, B. J., Hemphill, S. A., Toumbourou, J. W., Catalano, R. F., \& Patton, G. C. (2007). Prevalence of substance use and delinquent behavior in adolescents from Victoria, Australia and Washington State, United States. Health Education \& Behavior, 34, 634650 .

Muggah, R. (2015). A manifesto for the fragile city. Journal of International Affairs, 68, 19-36.

National Research Council. (2003). Cities transformed: Demographic change and its implications in the developing world. Washington, DC: National Academics Press.

Ndugwa, R. P., Kabiru, C. W., Cleland, J., Beguy, D., Egondi, T., Zulu, E. M., \& Jessor, R. (2010). Adolescent problem behavior in Nairobi’s informal settlements: Applying 
problem behavior theory in sub-Saharan Africa. Journal of Urban Health, 88, S298S317.

Nezlek, J. B. (2008). An introduction to multilevel modeling for social and personality psychology. Social and Personality Psychology Compass, 2, 842-860.

Niehaus, E., Campbell, C. M., Inkelas, K. K. (2014). HLM behind the curtain: Unveiling decisions behind the use and interpretation of HLM in higher education research. Research in Higher Education, 55, 101-122.

Oesterle, S., Hawkins, J. D., Fagan, A. A., Abbott, R. D., \& Catalano, R. F. (2014). Variation in the sustained effects of the Communities That Care prevention system on adolescent smoking, delinquency, and violence. Prevention Science, 15, 138-145.

O’Malley, P. M., Johnston, L. D., Bachman, J. G., Schulenberg, J. E., \& Kumar, R. (2006). How substance use differs among American secondary schools. Prevention Science, 7, 409420 .

Parks, M. J. (2014). Urban poverty traps: Neighbourhoods and violent victimisation and offending in Nairobi, Kenya. Urban Studies, 51, 1812-1832.

Parks, M. J., Dodoo, N-A. F., \& Ayernor, P. K. (2014). Applying neighborhood-effect research to a global south city: A case study of collective efficacy in Accra, Ghana's low-income areas. The Global South, 8, 119-138.

Patton, G. C., Sawyer, S. M., Santelli, J. S., Ross, D. A., Afifi, R., ..., Viner, R. M. (2016). Our future: A Lancet commission on adolescent health and wellbeing. Lancet, 387, 24232478.

Raudenbush, S.W., \& Bryk, A. S. (2002). Hierarchical linear models: Applications and data analysis methods. Newbury Park, CA: Sage.

Reardon, S., \& Firebaugh, G. (2002). Measures of multigroup segregation. Sociological Methodolgy, 32, 33-67.

Sampson, R. J. (2012). Great American city: Chicago and the enduring neighborhood effect. Chicago, IL: University of Chicago Press.

Sawyer, S. M., Afifi, R. A., Bearinger, L. H., Blakemore, S.-J., Dick, B.,.., Patton, G. C. (2012). Adolescence: A foundation for future health. Lancet, 379, 1630-1640.

Shaw, C. R., \& McKay, H. D. (1942). Juvenile delinquency and urban areas. Chicago, IL: University of Chicago Press. 
Solomon, R., Solomon, S., Minaie, M. G., Catalano, R., \& Toumbourou, J. W. (2012). How are adolescents faring in the rapidly modernizing city of Mumbai? Across-national comparison of adolescents in Mumbai India, Washington State in the USA and Victoria in Australia. Mumbai, India: India Institute for Child and Adolescence Health Research.

Stokols, D. (1992). Establishing and maintaining healthy environments: Toward a social ecology of health promotion. American Psychologist, 47, 6-22.

Sweeten, G. (2012). Scaling criminal offending. Journal of Quantitative Criminology, 28, 533557.

Viner, R. M., Ozer, E. M., Denny, S., Marmot, M., Resnick, M.,..., Currie, C. (2012). Adolescence and the social determinants of health. Lancet, 379, 1641-1652.

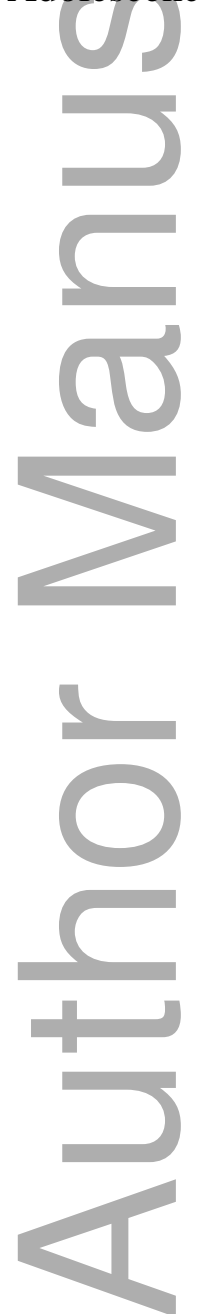




\begin{tabular}{|c|c|c|c|c|c|c|c|c|c|c|c|c|}
\hline & \multicolumn{4}{|c|}{ Mumbai, India ${ }^{a}$} & \multicolumn{4}{|c|}{ Victoria, Australia ${ }^{b}$} & \multicolumn{4}{|c|}{ Washington State, U.S. } \\
\hline Variables & Mean & (SD) & Min & Max & Mean & (SD) & Min & Max & Mean & (SD) & Min & Max \\
\hline \multicolumn{13}{|l|}{ Individual-level } \\
\hline Delinquency & 0.25 & $(0.96)$ & 0 & 10 & 0.48 & $(1.11)$ & 0 & 10 & 0.54 & $(1.13)$ & 0 & 10 \\
\hline $\operatorname{Sex}($ male $=1)$ & 0.55 & & 0 & 1 & 0.48 & & 0 & 1 & 0.49 & & 0 & 1 \\
\hline Age & 13.28 & $(1.30)$ & 10 & 20 & 13.92 & $(1.06)$ & 11 & 16 & 14.13 & $(1.10)$ & 12 & 17 \\
\hline Urban resic & $\sim$ & & $\sim$ & $\sim$ & 0.54 & & 0 & 1 & 0.61 & & 0 & 1 \\
\hline Race/ethnicity ${ }^{1}$ & $\sim$ & & $\sim$ & $\sim$ & 0.90 & & 0 & 1 & 0.67 & & 0 & 1 \\
\hline Religion $^{2}$ & 0.74 & & 0 & 1 & $\sim$ & & $\sim$ & $\sim$ & $\sim$ & & $\sim$ & $\sim$ \\
\hline Mobility & 1.71 & $(0.64)$ & 1 & 4 & 1.97 & $(0.64)$ & 1 & 4 & 2.18 & $(0.69)$ & 1 & 4 \\
\hline Low school commitment & 1.71 & $(0.50)$ & 1 & 5 & 2.26 & $(0.63)$ & 1 & 5 & 2.25 & $(0.59)$ & 1 & 5 \\
\hline Sensation seeking & 1.37 & $(0.74)$ & 1 & 6 & 2.37 & $(1.25)$ & 1 & 6 & 2.34 & $(1.25)$ & 1 & 6 \\
\hline Peer delinqueney & 0.17 & $(0.40)$ & 0 & 4 & 0.28 & $(0.48)$ & 0 & 4 & 0.30 & $(0.52)$ & 0 & 4 \\
\hline Peer substance abuse & 0.12 & $(0.37)$ & 0 & 4 & 0.93 & $(0.97)$ & 0 & 4 & 0.84 & $(1.04)$ & 0 & 4 \\
\hline Poor family management & 2.00 & $(0.59)$ & 1 & 4 & 1.75 & $(0.50)$ & 1 & 4 & 1.66 & $(0.52)$ & 1 & 4 \\
\hline \multicolumn{13}{|l|}{ Parent education } \\
\hline Primary & 0.58 & & 0 & 1 & 0.44 & & 0 & 1 & 0.11 & & 0 & 1 \\
\hline Secondary & 0.14 & & 0 & 1 & 0.24 & & 0 & 1 & 0.49 & & 0 & 1 \\
\hline Post-secondary & 0.20 & & 0 & 1 & 0.27 & & 0 & 1 & 0.38 & & 0 & 1 \\
\hline Do not know & 0.09 & & 0 & 1 & 0.05 & & 0 & 1 & 0.03 & & 0 & 1 \\
\hline Community disorganization & 1.90 & $(0.65)$ & 1 & 4 & 1.48 & $(0.52)$ & 1 & 4 & 1.49 & $(0.57)$ & 1 & 4 \\
\hline
\end{tabular}

This article is protected by copyright. All rights reserved 


\begin{tabular}{|c|c|c|c|c|c|c|c|c|c|c|c|c|}
\hline Socioeconomic level $^{3}$ & 1.53 & $(0.55)$ & 1.00 & 2.95 & 1.80 & $(0.42)$ & 1.00 & 2.90 & 2.24 & $(0.35)$ & 1.15 & 2.95 \\
\hline Community disorganization & 1.94 & $(0.32)$ & 1.16 & 2.77 & 1.51 & $(0.18)$ & 1.18 & 2.15 & 1.51 & $(0.24)$ & 1.06 & 2.30 \\
\hline Mobility & 1.73 & $(0.33)$ & 1.21 & 2.92 & 1.97 & $(0.27)$ & 1.39 & 2.50 & 2.19 & $(0.33)$ & 1.51 & 3.17 \\
\hline Ethnic/racial diversity & $\sim$ & $\sim$ & $\sim$ & $\sim$ & 0.15 & $(0.17)$ & 0.00 & 0.58 & 0.45 & $(0.19)$ & 0.00 & 0.90 \\
\hline Religious diversity & 0.38 & $(0.18)$ & 0.00 & 0.71 & $\sim$ & $\sim$ & $\sim$ & $\sim$ & $\sim$ & $\sim$ & $\sim$ & $\sim$ \\
\hline Caste diversity & 0.46 & $(0.21)$ & 0.00 & 0.91 & $\sim$ & $\sim$ & $\sim$ & $\sim$ & $\sim$ & $\sim$ & $\sim$ & $\sim$ \\
\hline
\end{tabular}

This article is protected by copyright. All rights reserved 


\begin{tabular}{|c|c|c|c|}
\hline Measures & Mumbai, India & Victoria, Australia & Washington State, U.S. \\
\hline Individual-level variance component & 2.075 & 1.888 & 2.044 \\
\hline School-level variance component & $0.778 * * *$ & $0.352 * * *$ & $0.128 * * *$ \\
\hline Intraclass correlation & 0.273 & 0.157 & 0.059 \\
\hline \multicolumn{4}{|c|}{$\begin{array}{l}\text { Notes. India: individual } \mathrm{N}=3,717 \text {, school } \mathrm{N}=98 \text {; Australia: individual } \mathrm{N}=1842 \text {, school } \mathrm{N}=102 ; \mathrm{U} . \mathrm{S} \text {.: } \\
\text { individual } \mathrm{N}=1,828 \text {, school } \mathrm{N}=97 ; * * * \mathrm{p}<=.001 \text {; indicates whether there is a statistically significant amount } \\
\text { of school-level variance. }\end{array}$} \\
\hline
\end{tabular}

of school-level variance.

This article is protected by copyright. All rights reserved 


\begin{tabular}{|c|c|c|c|c|c|c|c|c|c|}
\hline \multirow[b]{2}{*}{ Variables } & \multicolumn{3}{|c|}{ Mumbai, India $^{a}$} & \multicolumn{3}{|c|}{ Victoria, Australia $^{\text {b }}$} & \multicolumn{3}{|c|}{ Washington State, U.S. } \\
\hline & $\mathrm{b}$ & (S.E.) & $\mathrm{ERR}^{\mathrm{d}}$ & $\mathrm{b}$ & (S.E.) & ERR & $\mathrm{b}$ & (S.E.) & ERR \\
\hline \multicolumn{10}{|l|}{ Individual-level } \\
\hline Sex $($ male $=1)$ & 0.45 & $(0.14)$ & 1.57 & 0.53 & $(0.10)$ & 1.70 & 0.48 & $(0.10)$ & 1.62 \\
\hline Age & 0.08 & $(0.05)$ & $1.08+$ & 0.06 & $(0.07)$ & 1.06 & 0.02 & $(0.05)$ & 1.02 \\
\hline Urban resident & $\sim$ & $\sim$ & $\sim$ & -0.17 & $(0.16)$ & 0.84 & -0.23 & $(0.09)$ & 0.79 \\
\hline Race/ethnicity $^{1}$ & $\sim$ & $\sim$ & $\sim$ & -0.29 & $(0.17)$ & $0.75+$ & -0.09 & $(0.12)$ & 0.92 \\
\hline Religion $^{2}$ & 0.09 & $(0.16)$ & 1.09 & $\sim$ & $\sim$ & $\sim$ & $\sim$ & $\sim$ & $\sim$ \\
\hline Mobility & 0.13 & $(0.11)$ & 1.14 & 0.04 & $(0.08)$ & 1.05 & 0.07 & $(0.06)$ & 1.07 \\
\hline Low school commitment & 0.23 & $(0.12)$ & $1.47+$ & 0.30 & $(0.07)$ & 1.35 & 0.16 & $(0.09)$ & $1.17+$ \\
\hline Sensation seeking & 0.39 & $(0.06)$ & 1.48 & 0.26 & $(0.04)$ & 1.30 & 0.29 & $(\mathbf{0 . 0 3})$ & 1.33 \\
\hline Peer delinquency & 0.61 & $(0.11)$ & 1.85 & 0.48 & $(0.09)$ & 1.61 & 0.47 & $(0.08)$ & 1.60 \\
\hline Peer substance abuse & 0.03 & $(0.14)$ & 1.03 & 0.32 & $(0.05)$ & 1.38 & 0.24 & $(0.05)$ & 1.27 \\
\hline Poor family management & 0.38 & $(\mathbf{0 . 1 0})$ & 1.46 & 0.29 & $(0.10)$ & 1.34 & 0.24 & $(0.08)$ & 1.27 \\
\hline \multicolumn{10}{|l|}{ Parent education } \\
\hline Secondary & 0.05 & $(0.19)$ & 1.05 & -0.06 & $(0.11)$ & 0.94 & -0.09 & $(0.16)$ & 0.91 \\
\hline Post-secondary & 0.04 & $(0.24)$ & 1.04 & -0.33 & $(0.12)$ & 0.72 & -0.22 & $(0.17)$ & 0.80 \\
\hline Do not know & -0.15 & $(0.24)$ & 0.86 & 0.09 & $(0.22)$ & 1.09 & -0.25 & $(0.28)$ & 0.78 \\
\hline $\begin{array}{l}\text { Community disorganization } \\
\text { School-level }\end{array}$ & 0.29 & $(\mathbf{0 . 1 3})$ & 1.34 & 0.17 & $(0.07)$ & 1.18 & 0.16 & $(0.08)$ & 1.18 \\
\hline Socioeconomic level $^{3}$ & 0.03 & $(0.15)$ & 1.03 & -0.34 & $(0.17)$ & 0.71 & -0.29 & $(0.16)$ & $0.75+$ \\
\hline Community disorganization & 2.07 & $(0.40)$ & 7.92 & 1.23 & $(\mathbf{0 . 4 5})$ & 3.42 & 0.17 & $(0.28)$ & 1.19 \\
\hline Mobility & -0.07 & $(0.22)$ & 0.93 & -0.33 & $(0.27)$ & 0.72 & 0.45 & $(0.14)$ & 1.56 \\
\hline
\end{tabular}

This article is protected by copyright. All rights reserved 


\begin{tabular}{|c|c|c|c|c|c|c|c|c|c|}
\hline Ethnic/racial diversity & $\sim$ & $\sim$ & $\sim$ & 0.29 & $(0.41)$ & 1.33 & -0.21 & 0.25 & 0.81 \\
\hline Religious diversity & 0.39 & $(0.47)$ & 1.48 & $\sim$ & $\sim$ & $\sim$ & $\sim$ & $\sim$ & $\sim$ \\
\hline Caste diversity & -0.41 & $(0.41)$ & 0.66 & $\sim$ & $\sim$ & $\sim$ & $\sim$ & $\sim$ & $\sim$ \\
\hline \multicolumn{10}{|l|}{ Variance components } \\
\hline Individual level & \multicolumn{3}{|l|}{1.52} & \multicolumn{3}{|l|}{0.92} & \multicolumn{3}{|l|}{1.09} \\
\hline School level & \multicolumn{3}{|l|}{$0.41 * * *$} & \multicolumn{3}{|l|}{$0.28 * * *$} & \multicolumn{3}{|l|}{$0.04 * *$} \\
\hline \multicolumn{10}{|c|}{$\begin{array}{l}\text { Notes. All bolded coefficients are statistically significant: } \mathrm{p}<.05 ;{ }^{\text {a }} \text { school } \mathrm{N}=98 \text {, individual } \mathrm{N}=3717 ;{ }^{\mathrm{b}} \mathrm{school} \mathrm{N}=102 \text {, individual } \mathrm{N}=1842 ;{ }^{\mathrm{c}} \mathrm{school} \\
\mathrm{N}=97 \text {, individual } \mathrm{N}=1828 ;{ }^{\mathrm{d}} \text { Event Rate Ratio; }{ }^{1} \text { for Australia sample: } 1=\text { Australian, } 0=\text { other; for U.S. sample: } 1=\text { white, } 0=\text { non-white; }{ }^{2} 1=\mathrm{Hindu} \text {, } \\
0=\text { other religion; }{ }^{3} \text { Measured as mean level of education aggregated from parents' mean education; }+\mathrm{p}<.10 ;{ }^{*} \mathrm{p}<=.01 ;{ }^{* * *} \mathrm{p}<=.001 ; \text { robust } \\
\text { standard errors in parentheses; Primary education is omitted and used as the reference for parent education. }\end{array}$} \\
\hline
\end{tabular}

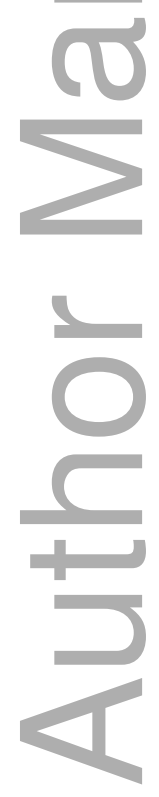

This article is protected by copyright. All rights reserved 
Figure 1. Mean comparisons of social disorganization factors

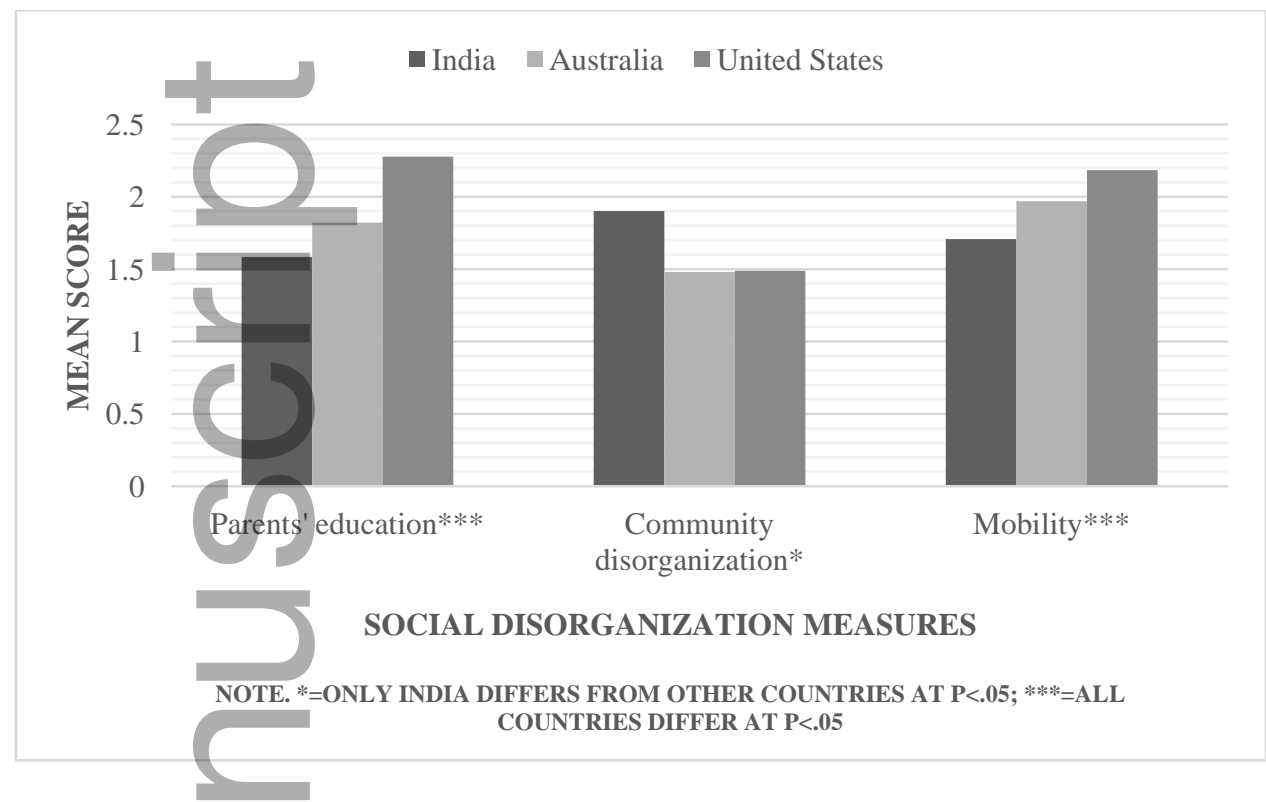

Figure 2. Mean comparisons of other risk factors

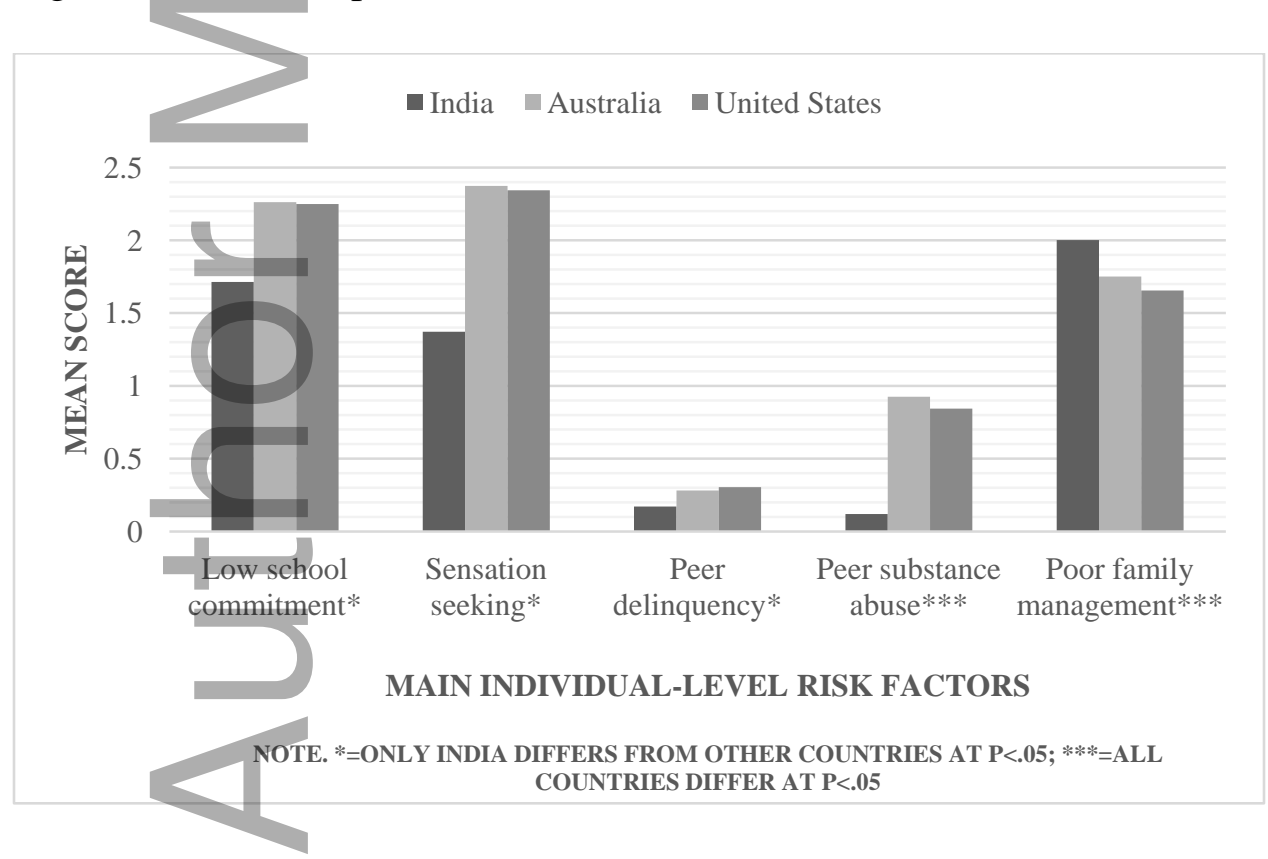




\section{University Library}

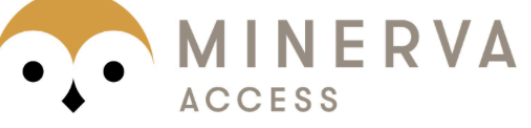

A gateway to Melbourne's research publications

Minerva Access is the Institutional Repository of The University of Melbourne

Author/s:

Parks, MJ;Solomon, RJ;Solomon, S;Rowland, BC;Hemphill, SA;Patton, GC;Toumbourou, JW

Title:

Delinquency, School Context, and Risk Factors in India, Australia, and the United States: Implications for Prevention

Date:

2020-01-01

\section{Citation:}

Parks, M. J., Solomon, R. J., Solomon, S., Rowland, B. C., Hemphill, S. A., Patton, G. C. \& Toumbourou, J. W. (2020). Delinquency, School Context, and Risk Factors in India, Australia, and the United States: Implications for Prevention. JOURNAL OF RESEARCH ON ADOLESCENCE, 30 (S1), pp.143-157. https://doi.org/10.1111/jora.12455.

Persistent Link:

http://hdl.handle.net/11343/284523 